\title{
Artikel
}

\section{Op de toekomst voorbereid}

\author{
Digitale toegankelijkheid onder de loep
}

\author{
Mr. D.C. Houtzager*
}

\section{Inleiding}

Even een maaltijd bestellen bij een bezorgdienst, een afspraak maken voor een controle in het ziekenhuis, een instructiefilmpje voor een recept bekijken op YouTube. Voor veel mensen is dat een vanzelfsprekendheid in de huidige digitale omgeving. Veel mensen met een beperking kunnen echter in de praktijk geen gebruik maken van dergelijke digitale diensten. Wie een computermuis niet kan bedienen, is afhankelijk van scrollen met het toetsenbord; wie een auditieve beperking heeft, kan een gesproken instructie niet volgen. Alleen als die technische mogelijkheden bestaan, is de dienst zelf toegankelijk. Uit onderzoek dat in 2015 is uitgevoerd naar toegankelijkheid van websites van gemeenten ${ }^{1}$ blijkt dat slechts een minderheid van die sites door mensen met een beperking gebruikt kon worden.

De noodzaak van toegankelijkheid van overheidsinstellingen mag duidelijk zijn. Steeds meer dienstverlening door de overheid heeft alleen een digitale toegang, van het maken van een afspraak voor het aanvragen van een rijbewijs tot de berichtgeving van de Belastingdienst. ${ }^{2}$ Uit het onderzoek bleek dat veel gemeenten hun websites niet op orde hebben. Mensen met beperkingen kun-

* Mr. D.C. (Dick) Houtzager is collegelid bij het College voor de Rechten van de Mens en hoofdredacteur van Handicap \& Recht.

1. G. Copinga e.a.: Digitale toegankelijkheid van gemeentelijke websites. QuickScan naar de stand van zaken per mei 2015. Hilversum: Stichting Drempelvrij (2015).

2. Zie bijvoorbeeld: Nationale ombudsman, 'Het verdwijnen van de blauwe envelop. Een onderzoek naar de digitalisering van het berichtenverkeer van de Belastingdienst', Rapport 2016/030, 5 april 2016. nen niet alle onderdelen van de site gebruiken, doordat bijvoorbeeld het doorklikken naar een achterliggend formulier niet mogelijk is, of omdat de routebeschrijving naar een gebouw alleen met behulp van een kaart werd aangegeven. Slechts 7 procent van alle gemeenten voldeed aan de internationale normen voor toegankelijkheid. Inmiddels hebben veel gemeenten stappen genomen om hun websites te verbeteren.

De afhankelijkheid van digitale diensten is ook in de private sfeer sterk toegenomen. Ziekenhuizen, zorgverzekeraars, banken, openbaarvervoerorganisaties, telecombedrijven, sportverenigingen en webwinkels geven in veel gevallen de eerste toegang tot hun diensten via het web en, in toenemende mate, via mobiele applicaties. Dat vergt niet alleen toenemende vaardigheid in het gebruik van dergelijke voorzieningen, maar het stelt ook eisen aan de toegankelijkheid voor mensen met een beperking. Ook op dit terrein moet nog veel vooruitgang worden geboekt, blijkt uit onderzoek van 100 veelgebruikte Nederlandse websites. Veel sites in de private sector scoren middelmatig of slecht. ${ }^{3}$

Bijzondere aandacht in dat verband verdient het onderwijs. Scholen in het primair en voortgezet onderwijs maken steeds vaker gebruik van gemengde vormen van lesmethoden: naast boeken ook onlinelesmateriaal; hetzelfde geldt voor organisatorische voorzieningen: roosters en toetsresultaten zijn veelal alleen nog digitaal beschikbaar via toepassingen als Magister. In het hoger onderwijs is digitaal communiceren al de norm.

De gevorderde techniek kan aan de andere kant juist bijdragen aan een grotere mate van autonomie, en daarmee aan inclusie van mensen met een beperking. Op veel smartphones en andere apparaten is het gebruik van een

3. R. Beenen e.a.: Monitor 2016 Toegankelijkheid Websites Nederland, Utrecht: Stichting Accessibility (2016). 
voice-overfunctie, groot lettertype en hoog contrast in te stellen. Met dergelijke functies zijn veel apps en websites bruikbaar voor mensen die een visuele of andere beperking hebben. De door anderen geleverde applicaties en software moeten dan wel zijn afgestemd op het gebruik van deze functies. Daar is nog veel winst te behalen.

Het ontwerpen van toegankelijke digitale diensten hoeft voor aanbieders van diensten geen extra belasting in de vorm van hoge kosten of inzet van middelen te zijn. De toegankelijkheid is inmiddels vastgelegd in een wereldwijde standaard. Een internationaal consortium van ITdeskundigen, $\mathrm{W}^{3} \mathrm{C}^{4}$, heeft een set van standaarden ontwikkeld. Dat is gebeurd in opeenvolgende versies van de Web Content Accessibility Guidelines (WCAG). ${ }^{5}$ De WCAG-normen worden algemeen aanvaard als leidend met betrekking tot toegankelijkheid van websites en digitale diensten. ${ }^{6}$ Wanneer een website of een mobiele toepassing aan die normen voldoet, is de toegankelijkheid goed geborgd. Ook zijn er weinig of geen extra werkzaamheden nodig als bij het eerste ontwerp rekening wordt gehouden met toegankelijkheid. In veel gevallen is er dan ook geen sprake van onwilligheid om een toegankelijk systeem te hebben of te onderhouden, maar eerder een gebrek aan bewustzijn. Het inclusief ontwerpen van digitale dienstverlening lijkt niet hoog op de beleidsagenda van organisaties te staan, in tegenstelling tot onderwerpen als privacy en beveiliging van ICT-systemen. Die lijken een hogere status te hebben, wellicht omdat organisaties bestaande wetgeving kennen, zoals de Wet bescherming persoonsgegevens. Een poging tot digitale inbraak kan eveneens dienen als wake-upcall om de beveiliging van een site uit te breiden. Wetgeving omtrent digitale toegankelijkheid bestaat inmiddels ook, zoals onderstaand besproken wordt. Wellicht moet de bewustwording op dat terrein nog groeien. Dat zou ook ten goede komen aan mensen met een beperking zelf. Velen van hen zoeken het probleem bij zichzelf; ze accepteren dat er dingen zijn die ze niet kunnen, terwijl het vaak het systeem is dat voor de ontoegankelijkheid zorgt.

Meer bewustwording op dit terrein is daarom nuttig om ontwikkelingen te stimuleren. Maar naast bewustwording is ook kennis van de geldende (en komende) regelgeving van belang. Welke onderwerpen bestrijkt de wet- en regelgeving in Nederland?

\section{Wet- en regelgeving}

In het navolgende wordt ingegaan op internationale en nationale wetgeving. Eerst bespreek ik het VN-verdrag

4. W3C heeft onder andere de webtaal HTML ontworpen; zie: www.w3. org.

5. Inmiddels wordt versie WCAG 2.1 ontwikkeld, om tegemoet te komen aan het toegenomen gebruik van smartphones en tablets: https://www. w3.org/WAI/.

6. Van de laatst geldende standaard is ook een ISO-norm gemaakt: ISO/ IEC 40500:2012.
Handicap, vervolgens ga ik in op Europeesrechtelijke ontwikkelingen, om te eindigen met de nationale wetgeving.

\subsection{VN-verdrag Handicap}

Het Internationaal Verdrag inzake de Rechten van Personen met een Handicap, verder aan te duiden als IVRPH of VN-verdrag Handicap, heeft als uitgangspunt dat mensen ongeacht hun handicap deel kunnen uitmaken van de samenleving. ${ }^{7}$ Ten aanzien van toegankelijkheid zijn verschillende artikelen relevant. Artikel 4 IVRPH, dat de algemene verplichtingen van de lidstaten beschrijft, bepaalt dat staten zich verplichten om universeel ontwerp te bevorderen. Onder universeel ontwerp wordt verstaan het 'ontwerpen van producten, omgevingen, programma's en diensten die door iedereen in de ruimst mogelijke zin gebruikt kunnen worden zonder dat een aanpassing of een speciaal ontwerp nodig is. "Universeel ontwerp" omvat tevens ondersteunende middelen voor specifieke groepen personen met een handicap, indien die nodig zijn. ${ }^{8}$ De staat moet bevorderen dat ontwerpers van software en hun opdrachtgevers computersystemen zo inrichten dat geen aparte voorzieningen meer nodig zijn voor mensen die, om welke reden dan ook, geen gebruik van die systemen kunnen maken.

Met betrekking tot toegankelijkheid is artikel 9 IVRPH van belang. Dit artikel heeft een breed werkingsgebied, dat de staat verplicht om passende maatregelen te nemen om toegankelijkheid te bevorderen. Naast de fysieke omgeving, zoals gebouwen, wegen en vervoer, worden ook de terreinen informatie, communicatie en elektronische diensten genoemd. Artikel 9, lid 2, onderdeel h, IVRPH geeft daarbij een praktisch handvat: toegankelijke technologieën moeten in een vroeg stadium ontworpen, ontwikkeld, geproduceerd en gedistribueerd worden, om deze 'tegen minimale kosten' toegankelijk te maken. Door de opstellers van het verdrag is kennelijk rekening gehouden met het bezwaar van hoge kosten van het aanpassen van bestaande systemen.

Artikel 9 IVRPH betreft een van de economische, sociale en culturele rechten. Dergelijke rechten vergen een inspanning van de overheid. De staat moet maatregelen nemen om tot daadwerkelijke verwezenlijking te komen. Dat mag geleidelijk, dat wil zeggen dat er wat tijd overheen mag gaan voordat de maatregelen effect hebben. Dat blijkt uit artikel 4, lid 2, IVRPH. ${ }^{9}$ De verplichting houdt wel in dat er een tijdpad moet komen en dat er voldoende beschikbare middelen ingezet moeten worden om tot uitvoering van die maatregelen te komen.

\subsection{Europese Unie}

Ook de Europese Unie heeft het VN-verdrag Handicap geratificeerd; voor de Unie het eerste internationale mensenrechtenverdrag waar zij als internationaal orgaan aan gebonden is. Alle verplichtingen die uit het verdrag

\footnotetext{
Art. 3, onderdeel a, c en $\mathrm{f}$, IVRPH.

Art. 2 IVRPH.

Zie ook: J. Goldschmidt en E.M. Gispen: Ratificatie... en dan?, Utrecht: Studie- en Informatiecentrum Mensenrechten (2012), p. 11 e.v.
} 
voortvloeien zijn van toepassing op de Unie, inclusief de rapportageverplichting. Het CRPD-comité heeft de Unierapportage in 2016 besproken en zijn concluding observations gepubliceerd. Daarin is onder andere geconstateerd dat mensen met beperkingen in de EU niet altijd toegang tot informatie en communicatie hebben in toegankelijke vorm. Dat is een onderwerp dat rakt aan de vrijheid van meningsuiting in artikel 21 IVRPH. Het Comité heeft de Europese Unie daarom opgeroepen om werk te maken van wetgeving omtrent toegankelijke taal en technologieën, waaronder gebarentaal, braille, en andere communicatieformaten en -middelen.

\subsubsection{Toegankelijkheidsakte}

In het licht van onder andere het VN-verdrag Handicap, maar ook op basis van het VWEU (artikel 114) heeft de Europese Commissie een 'Strategie voor mensen met een handicap 2010-2020' opgesteld. ${ }^{10}$ Daarbij heeft de EU vooropgesteld dat barrières die de deelname aan de samenleving voor mensen met een beperking in de weg staan, weggenomen moeten worden. Om hier een begin mee te maken is het aanbod van producten en diensten gekozen. In december 2015 heeft de Commissie een voorstel voor de Europese Toegankelijkheidsakte naar buiten gebracht. ${ }^{11}$ De Akte, die de vorm van een richtlijn heeft, heeft als belangrijkste doel om het functioneren van de interne markt voor toegankelijke producten en diensten te bevorderen. Dat is de reden dat artikel 114 VWEU, over het functioneren van de interne markt, als rechtsbasis is genomen. Uiteenlopende wetgeving in de lidstaten moet daarom worden geharmoniseerd. Opvallend is dat de Commissie hier een duidelijke marktoverweging met een harmonisatiedoel heeft gekozen. De ene lidstaat met vergaande regelingen zou immers in een mindere concurrentiepositie komen te verkeren ten opzichte van de andere lidstaat die weinig beperkingen oplegt aan producenten of dienstverleners. Daarnaast wijst de Commissie ook op de taak die de EU heeft in het bevorderen van gelijke behandeling en de integratie van mensen met een beperking. Dat is vastgelegd in de artikelen 21 en 26 van het Handvest voor de Grondrechten.

De Commissie heeft een aantal terreinen gekozen die bij voorrang aanpassing van bestaande regels betreffen. Het gaat om een aantal producten en diensten die in het dagelijks leven veel gebruikt worden, zoals computers (de hardware), bank- en kaartautomaten, apparaten bedoeld voor telefonie en audiovisuele media, transportsystemen in de luchtvaart, het spoor, bussen en vervoer over water, e-commerce, e-boeken en bankdiensten. Veel van deze diensten betreffen ICT-systemen. De producten en diensten die vallen onder de Akte moeten voorzien zijn van communicatie door middel meer dan één zintuigelijk kanaal: mensen met verschillende beperkingen moeten er gebruik van kunnen maken. Ook worden eisen gesteld aan de leesbaarheid, volumecontrole

10. http://ec.europa.eu/social/main.jsp?catld=1137\&langld=nl.

11. 2015/0278(COD), Toegankelijkheidseisen voor producten en diensten. Zie: www.europarl.europa.eu/oeil/popups/summary.do?id=1414781\& $\mathrm{t}=\mathrm{d} \& \mathrm{l}=\mathrm{en}$. en er moeten alternatieven worden geboden voor gebruik met fijne motoriek en weinig spierkracht.

De vereisten gaan niet zo ver dat de wezenlijke functies van de producten en diensten moeten worden aangepast. Ook moeten ze geen onevenredige belasting voor de producent met zich meebrengen. De Commissie heeft getracht om vooral uitkomstgerichte voorschriften te ontwikkelen, met het oog op noodzakelijke innovaties. Kritiek op het voorstel is er, zowel van de kant van producenten als van belangenorganisaties. Producenten vinden dat de voorschriften te gedetailleerd zijn, waardoor hun mogelijkheden voor productontwikkeling worden beperkt. Belangenorganisaties hebben er onder andere voor gepleit om ook de fysieke omgeving waarin de producten en diensten gebruikt worden onder de werking van de Akte te brengen. ${ }^{12}$ Het Europees Parlement heeft een amendement over de toegankelijkheid van de gebouwde omgeving aangenomen. Daarin is bepaald dat bij nieuwbouw of substantiële renovaties aan toegankelijkheidseisen moet worden voldaan. ${ }^{13}$

Het Europees Parlement heeft op 14 september 2017 over het voorstel en de amendementen gestemd en het voorstel is aangenomen. In de komende periode is het aan de Raad, en daarmee de regeringen van de lidstaten, om in overleg met het Parlement een definitieve tekst tot stand te brengen.

\subsubsection{Richtlijn toegankelijkheid overheidscommunicatie}

Onder het Nederlands voorzitterschap heeft de Europese Raad Richtlijn 2016/2102 ${ }^{14}$ aangenomen, die de toegankelijkheid van communicatie op overheidswebsites en -apps moet verbeteren. De richtlijn, die op uiterlijk 23 september 2018 in Nederlandse wetgeving moet zijn omgezet, is ingesteld om de wildgroei aan wetgeving in de lidstaten te beteugelen. Ook is het de bedoeling dat kleinere bedrijven die software en dergelijke ontwikkelen op de interne markt in andere lidstaten hun diensten en programma's kunnen aanbieden. De geharmoniseerde wetgeving moet dat mogelijk maken. Groot voordeel van de richtlijn is dat tenminste van een standaard wordt uitgegaan, de Europese norm EN 301 549. Die standaard is ontwikkeld voor aanbestedingen van overheidsopdrachten en is gelijk aan de industrienorm WCAG 2.0 zoals die is ontwikkeld door W3C en die overal in de wereld als gezaghebbend wordt aanvaard.

12. www.edf-feph.org/newsroom/news/european-parliament-dont-missopportunity-meaningful-accessibility-act.

13. Aangepaste tekst van artikel 10 Voorstel Toegankelijkheidsakte: 'Member States shall ensure that the built environment used by clients of passenger transport services including the environment that is managed by service providers and by infrastructure operators as well as the built environment used by clients of consumer banking services, and customer services centres and shops under the scope of telephony operators shall, as regards the construction of new infrastructure or substantial renovations to existing infrastructure, comply with the accessibility requirements set out in Section $X$ of Annex $I$, in order to maximise their use by persons with disabilities. This shall be without prejudice to Union legal acts and national legislation for the protection of national treasures possessing artistic, historic and archaeological value.'

14. Richtlijn (EU) $2016 / 2102$ van het Europees Parlement en de Raad van 26 oktober 2016 inzake de toegankelijkheid van de websites en mobiele applicaties van overheidsinstanties (PB L 327 van 2.12.2016, p. 1-15). 
Bij de toegankelijkheid moet worden voldaan aan vier beginselen, zoals omschreven in de preambule nr. 37 van de richtlijn: 'waarneembaarheid, waaronder wordt verstaan dat de informatie en de componenten van de gebruikersinterface zodanig aan gebruikers moeten kunnen worden gepresenteerd dat zij kunnen worden waargenomen; bedienbaarheid, waaronder wordt verstaan dat de componenten van de gebruikersinterface en de navigatie bedienbaar moeten zijn; begrijpelijkheid, waaronder wordt verstaan dat de informatie en de werking van de gebruikersinterface begrijpelijk moeten zijn, en robuustheid, waaronder wordt verstaan dat content voldoende robuust moet zijn opdat hij op betrouwbare wijze wordt geïnterpreteerd door uiteenlopende useragents, waaronder hulptechnologieën.'

De norm houdt in dat alle inhoud van websites en mobiele apps toegankelijk moet zijn, inclusief kaarten voor navigatiedoeleinden. Als die niet leesbaar zijn voor mensen met beperkingen, moeten toegankelijke alternatieven worden geboden, zoals adressen of nabije bushaltes. Ook foto's en video's moeten toegankelijk worden gemaakt, bijvoorbeeld door beschrijving van het beeld of het meeleveren van ondertiteling.

Overheidsinstanties zijn verplicht de toegankelijkheidseisen toe te passen, met slechts een enkele uitzondering, als de toepassing een 'onevenredige last' met zich meebrengt. Denk daarbij aan maatregelen die een overheidsinstantie een buitensporige organisatorische of financiële last zouden opleggen, of die afbreuk zouden doen aan het vermogen van de instantie om haar doelstelling te verwezenlijken of informatie bekend te maken die nodig of relevant is voor haar taken en diensten.

In de richtlijn is een bepaling opgenomen over een klachtmogelijkheid. Voor burgers die klachten hebben over overheidswebsites en -apps moet een onafhankelijke klachteninstantie worden ingericht. De lidstaten moeten in 2022, vier jaar na de omzetting, een rapport aan de Europese Raad uitbrengen waarin de stand van zaken wordt beschreven.

Hoe de omzetting in Nederland zal plaatsvinden, komt in onderstaande paragraaf aan bod.

\section{Nederland}

In het onderstaande ga $\mathrm{ik}$ in op de regelgeving over de toegankelijkheid van websites en andere informatietechnologie. Daarbij komen eerst de overheidsinstanties aan de orde, vervolgens de private aanbieders.

\subsection{Overheden}

In het eerder aangehaalde onderzoek naar toegankelijke websites haalden overheidswebsites een redelijke score. De sites van het parlement, gemeenten en rijksoverheid behoorden tot de beter toegankelijke van de onderzochte websites. ${ }^{15}$

15. R. Beenen e.a., p. 4
Voor websites en applicaties die door Nederlandse overheden worden beheerd, gelden de overheidsstandaarden die beschreven zijn in de beleidsregels EN 301549 . Het gaat om een instructienorm voor de inkoop van ICTdiensten door de overheid vanaf $€ 50.000,{ }^{16}$ die de al genoemde standaard WCAG 2.0 omvat. In die overheidsnorm is vastgelegd dat van de toegankelijkheidseisen kan worden afgeweken als een dienst of product naar verwachting in onvoldoende mate wordt aangeboden, onvoldoende veilig of zeker functioneert, of om andere redenen van bijzonder gewicht. ${ }^{17}$ Hier gaat het om het 'pas toe of leg uit'-beginsel: het betreffende departement, afdeling of onderdeel moet jaarlijks motiveren waarom afgeweken is van de toegankelijkheidsstandaard. Omdat de norm enige vaagheid in zich heeft, bijvoorbeeld waar het gaat om 'redenen van bijzonder gewicht' en omdat er geen externe toetsing plaatsvindt, is er voor overheidsdiensten een grote beleidsvrijheid om niet aan de norm te voldoen. Naar aanleiding van de komende inwerkingtreding van Europese Richtlijn 2016/2102 en van de ratificatie van het VN-verdrag Handicap heeft de minister van BZK, verantwoordelijk voor het IT-beleid bij de overheid, besloten om van de standaard een verplichting te maken. ${ }^{18}$ Dat betekent dat in de komende Wet generieke digitale infrastructuur (Wet GDI) een bepaling wordt opgenomen die het 'pas toe of leg uit'-beginsel vervangt door een dwingende norm. Dat is naar mijn mening een goede invulling van de verdragsverplichting uit artikel 9 IVRPH. In dat artikel wordt gevraagd om passende maatregelen die de toegang van mensen met een beperking op voet van gelijkheid met anderen garanderen tot informatie- en communicatiediensten. Daarbij zijn wel enkele uitzonderingen opgenomen, zoals voor het gebruik van onlinekaarten en het beheer van erfgoedcollecties (artikel 2 Wet GDI) en de algemene uitzondering dat een overheidsinstantie kan afzien van de toepassing van de toegankelijkheids-standaard voor zover dit een onevenredige last met zich mee brengt (artikel 3 Wet GDI). Het orgaan moet daar een verklaring over publiceren. Het monitoren van de voortgang ligt bij de minister van BZK. Hoewel deze uitzonderingen aan overheidsorganen nog steeds een zekere vrijheid laten om te bepalen dat een bepaalde toegankelijkheidsstandaard onevenredig belastend is, denk ik dat de beleidsmarge die het 'pas toe of leg uit'-beginsel met zich meebracht, verleden tijd wordt. De uitwerking van de verplichting vindt plaats in een $\mathrm{AMvB}$, het Besluit digitale toegankelijkheid overheid. Dat wordt op termijn gekoppeld aan de Wet GDI. De standaard EN 301549 is een integraal onderdeel van de normen in het besluit.

16. Besluit van de staatssecretaris van Economische Zaken van 8 november 2008, nr. WJZ/8157380, tot vaststelling Instructie rijksdienst inzake aanschaf ICT-diensten en ICT-producten.

17. Besluit van de staatssecretaris van Economische Zaken van 8 november 2008, nr. WJZ/8157380, tot vaststelling Instructie rijksdienst inzake aanschaf ICT-diensten en ICT-producten, art. 3.

18. Wetsontwerp Regels inzake de generieke digitale infrastructuur (Wet generieke digitale infrastructuur) van 29 augustus 2017, memorie van toelichting, p. 5. 
Het wetsontwerp GDI is in september 2017 voor advisering voorgelegd aan de Autoriteit Persoonsgegevens en zal daarna naar de Tweede Kamer worden gestuurd. Op 1 januari 2019 moet de wet in werking treden. ${ }^{19}$

3.2 Private aanbieders van goederen en diensten Uit het recente onderzoek naar de toegankelijkheid van websites ${ }^{20}$ blijkt dat bedrijven in verschillende branches, zoals webwinkels, nieuwssites en energiebedrijven, hun websites nog onvoldoende op orde hebben. Geen enkele branche scoort goed, maar onder de bedrijven in die sectoren zijn er wel positieve uitschieters. Organisaties in de zorg, pensioenfondsen en banken hebben de toegankelijkheid iets beter geregeld. Mensen die voor het gebruik van een toetsenbord afhankelijk zijn en niet de muis kunnen gebruiken ondervinden vaak problemen; in de helft van de onderzochte websites voldoet de toetsenbordtoegankelijkheid niet. Dat is met name voor het invullen van onlineformulieren bezwaarlijk.

Sinds de uitbreiding van de WGBH/CZ op 14 juni 2016, mogen aanbieders van goederen en diensten geen onderscheid maken op grond van handicap of chronische ziekte. Daarbij moeten zij op verzoek aan mensen met een handicap of chronische ziekte in het individuele geval doeltreffende aanpassingen bieden. ${ }^{21}$ Volgens artikel $2 \mathrm{WGBH} / \mathrm{CZ}$ en de vaste uitleg van het College voor de Rechten van de Mens, dient een aanpassing geschikt en noodzakelijk te zijn om de belemmering op te heffen. Een aanpassing is geschikt als die in staat is de belemmering weg te nemen en een aanpassing is noodzakelijk als er geen ander, minder ingrijpend of goedkoper alternatief bestaat. Daarbij bestaat een onderzoeksplicht voor de aanbieder: deze moet, in overleg met de klant, nagaan welke aanpassing aan de eisen voldoet.

Er bestaat een uitzondering op de plicht tot het verrichten van een doeltreffende aanpassing. Die houdt in dat een aanbieder geen aanpassing hoeft te verrichten als dat voor hem een onevenredige belasting betekent. Om te bepalen wat onevenredig belastend is, wegen de omvang van de organisatie, de geraamde kosten, de operationele en technische haalbaarheid en de uitvoerbaarheid of veiligheid van de aanpassing mee. ${ }^{22} \mathrm{Bij}$ het treffen van een aanpassing in het geval van een ontoegankelijke website, is het de vraag hoe een dergelijke individuele aanpassing zou kunnen plaatsvinden. In sommige gevallen is een individuele oplossing denkbaar; bijvoorbeeld door een eerdere versie van een app, die wel toegankelijk was, ter beschikking te stellen aan een gebruiker met een beperking. ${ }^{23}$ In veel andere gevallen is een individuele aanpassing echter moeilijk voor te stellen, zonder de gehele website of app aan te passen. $\mathrm{Bij}$ een geschil zal de toets van de onevenredige belasting moeten uitwijzen of de omvorming van een gehele site of app van een aanbieder

19. Zie ook: https://www.digitoegankelijk.nl/beleid/wet-en-regelgeving.

20. R. Beenen e.a.: Monitor 2016 Toegankelijkheid Websites Nederland, Utrecht: Stichting Accessibility (2016), p. 4.

21. Zie uitgebreid: C.A. Goudsmit, 'Uitbreiding WGBH/CZ met goederen en diensten. Rechtsbescherming van personen met een handicap neemt toe', Handicap \& Recht 2016, nr. 1, p. 3-8.

22. Kamerstukken I/ 2013/14, 33990, 3, p. 7 en 8; nr. 11, p. 4

23. Oordeel College 2017-107, 4 oktober 2017 gevergd kan worden ten behoeve van een individuele klant.

Sinds 1 januari 2017 is een andere, nieuwe verplichting voor aanbieders van goederen en diensten in het leven geroepen. Met ingang van die datum draagt een aanbieder 'tenminste geleidelijk zorg voor de algemene toegankelijkheid voor personen met een handicap of chronische ziekte, tenzij dat voor hem een onevenredige belasting vormt' (artikel 2a WGBH/CZ). Voor anbieders van diensten die online of via apps worden aangeboden, houdt die regel in dat zij hun communicatie toegankelijk moeten maken. Welke normen daarvoor gelden, is nog niet duidelijk. In de bij artikel 2a WGBH/CZ behorende $\mathrm{AMvB},{ }^{24}$ die op 7 juni 2017 in werking is getreden, is wel een aanzet gedaan. In de AMvB wordt gesteld dat verschillende sectoren actieplannen moeten opstellen, waarin de geleidelijke verwezenlijking van de toegankelijkheid wordt gerealiseerd. Daarbij moeten tenminste voorzieningen van eenvoudige aard worden getroffen. Daar wordt onder verstaan een 'voorziening die op weinig ingrijpende wijze en zonder of met weinig kosten tot stand kan worden gebracht'. ${ }^{25}$ De vraag of een dergelijke voorziening een onevenredige belasting opwerpt, komt aan bod in artikel 7 van het Besluit. Daarin staat dat voor de beoordeling bijzonder rekening wordt gehouden met de omvang, de middelen en de aard van de organisatie of onderneming, de geraamde kosten, het geraamde nut voor personen met een handicap of chronische ziekte in het algemeen. Ook moet rekening worden gehouden met de frequentie en de duur van het gebruik van de relevante goederen en diensten en met de frequentie en de duur van de relatie met de verkoper of dienstverlener en de levensduur van de infrastructuur en de voorwerpen die voor de verlening van een dienst worden gebruikt.

Voor de onlineomgeving van aanbieders van diensten levert dat nog niet veel houvast op. Wel kan worden aangenomen dat een rechter, of het College, er genoegen mee zou nemen als de WCAG 2.0 (of de dan geldende versie van deze webstandaarden) toegepast wordt. Blijft over de vraag of van elke aanbieder kan worden gevergd om WCAG 2.0 toe te passen; voor sommige kleinere organisaties of bedrijven kan dat een onevenredige belasting opleveren.

\section{Conclusie}

Waar digitale techniek drempels voor mensen met een beperking kan wegnemen, is diezelfde techniek in veel gevallen ook een onoverkomelijke hindernis. Het toenemende aanbod van dienstverlening via het web en applicaties betekent dat mensen die reguliere apparaten als een muis of een beeldscherm niet kunnen gebruiken, worden uitgesloten. Dat brengt een verantwoordelijk-

Besluit van 7 juni 2017, houdende regels omtrent de algemene toegankelijkheid voor personen met een handicap of chronische ziekte (Besluit algemene toegankelijkheid).

25. Art. 6, lid 2, Besluit algemene toegankelijkheid. 
heid met zich mee voor dienstverleners die hun goederen en diensten online aanbieden. Om die reden is het van belang dat er regelgeving wordt ontwikkeld die voor bewustwording en regulering zorgt in zowel de publieke als de private sfeer. Die regelgeving lijkt te voldoen aan de noodzaak voor toegankelijkheid.

De wettelijke normen in Nederland worden onder andere ingevoerd als gevolg van de ratificatie van het $\mathrm{VN}$ verdrag Handicap en door Europese ontwikkelingen. Het VN-verdrag Handicap legt in algemene termen vast dat onlinediensten op voet van gelijkheid met anderen toegankelijk moeten zijn voor mensen met een beperking. Europese richtlijnen maken dat concreter, door te verwijzen naar de door de industrie ontwikkelde standaarden, zoals de norm EN 301 549. Regelgeving ten aanzien van de toegankelijkheid van overheidsdiensten loopt daarbij voorop, door de in 2016 aangenomen Richtlijn 2016/2102 over overheidsdiensten. De Europese richtlijn over de toegankelijkheid van digitale diensten in bepaalde sectoren in de private sfeer, de Toegankelijkheidsakte, is momenteel in de maak. $\mathrm{Na}$ implementatie zal die gunstige gevolgen hebben voor bijvoorbeeld de toegankelijkheid van de bankensector. Nederland zit intussen niet stil. Ter voorbereiding van de omzetting van Europese Richtlijn 2016/2102, is een apart onderdeel opgenomen in het wetsontwerp Generieke digitale infrastructuur. Daarmee wordt de relatieve vrijblijvendheid van het huidige systeem van 'pas toe of leg uit' vervangen door een verplichting tot aanpassing van de digitale omgeving.

Voor de private sector heeft de regering gekozen voor een insteek via de gelijkebehandelingswetgeving. De toegankelijkheidsnorm is geformuleerd in termen van gelijke behandeling en non-discriminatie. Er wordt een inspanning verwacht van aanbieders van goederen en diensten, om die voor iedereen aan te bieden. Ten aanzien van mensen met een beperking betekent dat dat er in veel gevallen actie ondernomen zal moeten worden, in de vorm van een individuele doeltreffende aanpassing of meer in algemene zin, het geleidelijk zorgen voor algemene toegankelijkheid. Wie zich daar niet aan houdt, loopt het risico verboden onderscheid te maken.

Of de aangepaste normen daadwerkelijk gaan betekenen dat mensen met een beperking meer gebruik kunnen maken van onlinedienstverlening zal de komende tijd moeten blijken. De betreffende wet- en regelgeving lijkt inmiddels voorlopig op de toekomst te zijn voorbereid. 